\title{
REFLEXÕES POLÍTICO-ECONÔMICAS E O ATELIER DE PROJETO DE ARQUITETURA EM TEMPOS DE PANDEMIA DA COVID-19
}

\author{
REFLEXIONES POLÍTICAS Y ECONÓMICAS Y EL PROYECTO DE ARQUITECTURA ATELIER EN \\ TIEMPOS DE PANDEMIA COVID-19
}

\section{POLITICAL AND ECONOMIC REFLECTIONS AND THE ARCHITECTURE PROJECT ATELIER IN COVID- 19 PANDEMIC TIMES}

\section{SILVA, HEITOR DE ANDRADE}

Arquiteto, Professor Adjunto da Universidade Federal do Rio Grande do Norte, e-mail: heitor.andrade@ufrn.abea.arq.br

\section{CONSIDERAÇÕES INICIAIS}

O ensino remoto de projeto de Arquitetura e Urbanismo (AU) no atual contexto de distanciamento social consiste em um tema da maior pertinência para estudantes, professor e projetistas. É importante mencionar alguns recortes desta análise. O primeiro refere-se à diferença entre o ensino de AU e o ensino de projeto. Compreendemos que o ensino de $\mathrm{AU}$ inclui componentes curriculares teóricos (situados no eixo fundamental das estruturas curriculares), atividades complementares (com distintas naturezas), estágio, TCC; já o ensino de projeto refere-se, objetivamente, ao propósito de promover o aprendizado por meio do exercício projetual de intervenção no espaço, remetendo, naturalmente, aos componentes de projeto (arquitetura, urbanismo e paisagismo), com significativa carga horária prática, ações integradas e, em muitos casos, tem se voltado para a promoção da aprendizagem baseada em problemas (que tem o propósito de desenvolver competências e habilidades para a resolução de situações-problema, em geral, reais).

Um outro recorte importante refere-se às diferenças entre o ensino remoto praticado neste momento de isolamento social e o Ensino a Distância (EaD). O ensino remoto realizado neste momento de distanciamento social assemelha-se a $\mathrm{EaD}$ unicamente pela mediação da tecnologia no processo educacional; em geral, preserva os mesmos princípios da educação presencial. Rêgo e Garcia (2020) observam que as atividades de ensino remoto são aplicadas pontualmente, como uma adaptação do ensino presencial auxiliado por tecnologias da informação (aplicativos e salas de aula virtuais); não consistem, portanto, uma modalidade de ensino. Podemos acrescentar que, em geral, ainda são bastante adotadas as atividades síncronas. $\mathrm{A} \mathrm{EaD,} \mathrm{de} \mathrm{acordo} \mathrm{com} \mathrm{as} \mathrm{autoras,} \mathrm{dispõe} \mathrm{de} \mathrm{um} \mathrm{ambiente} \mathrm{de} \mathrm{aprendizado} \mathrm{com}$ material didático pedagógico específicos, apoio de tutores e recursos tecnológicos próprios; trata-se de uma modalidade de ensino, com concepção didático-pedagógica (estrutura formal flexível, mas abrangendo conteúdos, atividades e o processo avaliativo discente), requerendo um ambiente virtual capaz de ser acessado simultaneamente por muitas pessoas, garantindo a disponibilização de vídeos, transmissões de aula, fórum, atividades em geral, etc. (RÊGO; GARCIA, 2020). Podemos acrescentar que nessa modalidade de ensino prevalecem as atividades assíncronas.

Inicialmente, abordaremos 0 assunto numa perspectiva contextual, com ênfase na política e na economia. Em seguida resgataremos a noção de atelier de projeto, enquanto instrumento pedagógico presente no ensino de $\mathrm{AU}$, fazendo um contraponto com esse momento atípico de ensino remoto no Brasil.

\section{O CONTEXTO POLÍTICO-ECONÔMICO E OS ATELIÊS DE PROJETO}

\section{0 contexto político e econômico atual}

Não temos como pensar nesta experiência de ensino remoto, mesmo que num contexto de excepcionalidade determinado pela pandemia da Covid-19, iniciada de forma mais evidente no Brasil em março de 2020, sem refletir sobre a atual crise do capitalismo tardio (ou novo liberalismo), com destaque 
para as mudanças recentes no mundo do trabalho, como bem ilustra o longa "Você não estava aqui", de Ken Loach. Nesse contexto, em que tudo se torna mercadoria ou bens de consumo, como preferirmos chamar, inclusive, serviços essenciais como saúde e educação, a massificação do produto passa, por meio das tecnologias da informação, de um modo de fazer artesanal para uma escala industrial com grande alcance em termos quantitativos e numéricos. Associado a isso, existe um processo de precarização do trabalho em diversos âmbitos, não sendo diferente no ensino superior brasileiro, assim como no ensino de AU. Nesse sentido, assistimos a uma "EaDização" da docência, numa referência a expressão "Uberização" do trabalho, usada recorrentemente por estudiosos das transformações sociais no mundo do trabalho. É necessária uma ampla e criteriosa análise das consequências dessas mudanças nesse processo de transição. Desse modo, a questão crucial que precisamos nos preocupar é: Como garantir condições adequadas de trabalho para os profissionais do ensino, um aprendizado de qualidade e uma adequada formação aos profissionais de AU?

Ao mesmo tempo em que se tem a interrupção de um processo de expansão das infraestruturas físicas e de gestão das universidades públicas - o que significou a ampliação considerável do número de vagas e a inclusão de estudantes enquadrados em segmentos sociais historicamente excluídos (na primeira década dos anos 2000) -, determinada, entre outras razões, pela PEC do teto de gastos públicos (241/55, de 2017); verifica-se um deslocamento do modo de aquisição de lucro nas IES privadas: do endividamento estudantil (FIES) para o EaD (que pressupõe a massificação do ensino). Nesse contexto, a ampliação do número de estudantes através do alcance das instituições no país, possibilitará, mesmo com mensalidades mais baixas e acessíveis, um maior lucro (WILDEROM; ARANTES, 2020).

Muito tem-se dito que a experiência do distanciamento social nos coloca diante de um "novo normal", em que a intensificação das tecnologias da informação (TI) será imprescindível para a realização das atividades mais determinantes da vida social. Não poderia ser diferente no cotidiano da profissão de AU. É importante dizer, todavia, que as TI já estão presentes no cotidiano da nossa prática de forma determinante há pelo menos três décadas, com recursos de comunicação via internet; mais recentemente, com o uso das plataformas BIM, do algoritmo (parametrização, etc.), para mencionar apenas alguns mais populares. A diferença é que com a determinação do isolamento social, o uso dessas e de outras formas de comunicação foram aceleradas e ampliadas. É válido acrescentar que princípios como a colaboração entre projetistas e usuários auxiliada por computador, que antes poderia ser realizada por meio de plataformas BIM (com as quais inclusive, muitos professores de projeto e estudantes ainda não estão plenamente familiarizados), passaram a acontecer por meio de recursos domésticos (plataformas de videoconferência), que viabilizam o compartilhamento de desenhos (croquis a mão livre fotografados, desenhos desenvolvidos com inúmeros apps, dentre outros) e discussões coletivas (plataformas de videoconferência, para mencionar apenas um exemplo).

Ainda é válido mencionar a crise na profissão de $A U$, que deixou, já a algum tempo, de exercer uma influência relevante na sociedade, sobretudo, no uso do projeto como instrumento mediador de conflitos e garantidor da qualidade do espaço. A pesquisa "Percepções da sociedade sobre Arquitetura e Urbanismo", CAU/BR-Datafolha, realizada no Brasil, em 2015, constatou que de $54 \%$ da população economicamente ativa que já construiu ou reformou imóvel residencial ou comercial, $85,40 \%$ fez o serviço sem contratar arquitetos ou engenheiros. É importante lembrar que o número de cursos de AU em 2020 é de aproximadamente 800 (na década de 1970 eram em torno de 30). Essa questão nos faz pensar sobre a pertinência e urgência de discutirmos formas de reconquistar e até redefinir o papel da profissão na sociedade. É preciso criar pautas e reassumir o caráter ativista da profissão.

Por fim, é necessário observar as diferenças de comportamento neste período de pandemia entre as Instituições de Ensino Superior (IES) privadas e públicas no Brasil. A maioria das IES privadas, praticamente, não parou no período do isolamento, em parte para garantir o pagamento das mensalidades, mas também por vislumbrar a "oportunidade" de testarem as suas ferramentas de EaD, mesmo que por meio de ferramentas de ensino remoto, que já estavam, inclusive, prontas para serem aplicadas ${ }^{1}$. Prática que tem significado um grande sacrifício para os professores, que têm precisado improvisar (com a sua infraestrutura doméstica, melhorando planos de internet, adquirindo equipamentos e criando espaços de trabalho em casa) e dobrar a sua carga de trabalho (se qualificando e replanejando as aulas, enquanto seguem com os seus compromissos cotidianos de sala de aula). Além disso, esses docentes estão precisando lidar com problemas (de ordem financeira, de saúde e gestão das atividades domésticas) pessoais e dos estudantes.

As IES públicas, salvo poucas exceções (como a FAUUSP), interromperam as aulas na graduação e realizaram diagnósticos da situação das suas comunidades acadêmicas, para planejar estratégias de retomada das atividades de ensino, sobretudo, considerando as diferentes condições dos estudantes. Os pressupostos declarados foram o de pensar formas de inclusão dos discentes menos estruturados para 
seguir no contexto do ensino remoto. Várias instituições adotaram medidas inclusivas, como os auxílios emergenciais, cursos de capacitação, dentre outras. É importante ressaltar que partiu das IES públicas um considerável número de pesquisas e ações de apoio à sociedade para mitigar os impactos da pandemia. Inicialmente, muitas implantaram os semestres suplementares, em que foi incentivada (não obrigatória) a oferta de componentes curriculares (existentes e novos), bem como facultada aos estudantes a matrícula (com limite de carga horária). Em seguida, no caso da UFRN, em setembro, foi retomado o semestre letivo obrigatório, interrompido no início do ano.

\section{0 atelier de projeto e a transição para o ensino remoto no Brasil}

O ensino de projeto de $A U$ está associado ao sentido do atelier, visto que é prática frequente para a promoção da aprendizagem e do exercício projetual. Em geral, associamos a noção de atelier ao espaço físico, princípios pedagógicos e estratégias metodológicas. Essencialmente, o atelier surge com o propósito de dotar o estudante (antes o aprendiz) das habilidades necessárias a um determinado saber-fazer (repassado por um mestre), a obra propriamente, que, posteriormente, assume a linguagem mais abstrata do projeto. Predomina, sobretudo em IES públicas, o modelo tradicional, que preserva o seu caráter artesanal: com uma limitada relação professor-aluno (em torno de 15:1); assessoramentos individualizados (ou para pequenas equipes); em geral, com uma carga horária (ch) maior do que a maioria dos componentes curriculares teóricos, podendo ultrapassar às 180 horas (em torno de 10 horas semanais) de atividade presencial e dedicando pelo menos $50 \%$ de sua ch com atividades práticas; reúne professores com diferentes competências (responsáveis por distintas matérias); estrutura-se no desenvolvimento de projetos como soluções a problemas concretos (reais) com distintas naturezas e escalas (arquitetura, urbanismo e paisagismo); pressupõe a interação entre docentes e discentes, mas sobretudo dos estudantes entre si. Existem, contudo, críticas ao modelo tradicional.

Sin embargo, el taller tradicional como tal, ya no se sostiene. Las condiciones de masividad, los cambios en la concepción de la profesión y la disciplina, la misma idea del docente como depositario del saber, del poder de decidir lo que está bien y lo que está mal, lo que es bello y lo que no lo es, y muchos etcéteras más, llevan necesariamente a replantear las prácticas y los lugares de estudiantes y docentes en esa concepción tradicional (PORTER; MIGLIOLI, 2017, s.p.).

O modelo tradicional conhecido de todos nós, praticamente, só se viabiliza em condições específicas, que garantam, ao menos, a referida relação professor-aluno e as condições físicas para realização de atividades presenciais. Esse modelo é predominantemente encontrado nas IES públicas e algumas IES privadas mais reconhecidas nos meios profissionais, sobretudo por conseguirem garantir um número de professores condizente com o número de estudantes. Ainda, assim, podem ser observadas em algumas IES públicas algumas dificuldades para essas atividades ocorrerem no espaço físico da universidade, como por exemplo, a ausência de uma adequada infraestrutura para o uso de tecnologias (como ateliês equipados com computador, uma boa internet e, às vezes, tomadas suficientes). Assim, os ateliês em determinados estágios de desenvolvimento dos projetos se tornam espaços para acompanhamento e prestações de contas de como os trabalhos estão evoluindo. Essas questões, muitas vezes, servem de argumento em defesa do ensino de arquitetura a distância.

Brady (2020, s.p.) defende que o ensino de arquitetura online poderá ser uma realidade antes do que imaginamos. Segundo o autor, as aulas de projeto (um marco na vida dos arquitetos) também serão remotas, "provavelmente sem o contato pessoal que define essa experiência. Essa mudança eliminará muitos aspectos autodestrutivos da cultura atual de ateliê, [...]". Para o autor, atualmente, os cursos de arquitetura enfatizam projetos independentes dos estudantes, produzidos em pequenos grupos, em salas de aula específicas - os ateliês -, garantindo que os alunos passem mais tempo sozinhos uns com os outros do que com seus professores. Com isso, gera-se uma preferência entre os discentes para apresentar soluções de projeto auto justificadas, pouco fundamentadas. Observa, ainda, que devemos olhar para as mais recentes tecnologias da informação como um meio para conceber novos métodos de ensino e trabalho e que não deveríamos simplesmente substituir os existentes. "Uma vez que tudo que é transmitido através de um dispositivo ou pela internet pode ser rastreado e gravado, diferente das interações presenciais, a educação digital oferece muitas vantagens que ainda não foram totalmente exploradas" (Idem). Assim como em outros cursos, nos de arquitetura, pode-se pensar, com o auxílio da inteligência artificial, no uso de textos automatizados e o reconhecimento de voz como recursos para atendimento de uma grande quantidade de estudantes (por exemplo, o feedback de professores e entre alunos em pequenos grupos). Brady (2020, s.p.) reconhece "uma grande desvantagem: falta a exposição direta aos pensamentos, valores e processos de trabalho de outras pessoas". Ou seja, a ausência da interação entre os responsáveis pelo 
projeto. Os argumentos desse autor, apesar de coerentes, são perigosos no atual contexto de grandes pressões para a implantação do EaD, num país como grandes desigualdades sociais, como é o Brasil.

ARAÚJO (2007) corrobora com a questão de que ainda persiste uma prática em ateliês de projeto no âmbito acadêmico estruturada no trabalho individual, em que os estudantes desenvolvem seus projetos isoladamente (ou em pequenas equipes). No entanto, a autora ressalta a prática antiga da arquitetura da aprendizagem através da solução de problemas; o que é relativamente recente em outras áreas do conhecimento. Observa que o aumento da complexidade das questões espaciais reforça a ideia de que não é mais possível resolver problemas de forma isolada de seu contexto. Aliado a isso, ressalta-se o favorecimento da aprendizagem. A discussão sobre o projeto, o momento no qual o aluno interage com o professor, refletindo e expondo suas opiniões, é apontado como sendo o momento em que o aluno mais aprende. Tal é a importância em discutir o projeto, que os alunos procuram seus colegas, nos quais confiam, para discutirem sobre seus trabalhos. Os projetos de arquitetura quando desenvolvidos em equipe permitem que os alunos tenham com quem discutir de forma continuada, enriquecendo o processo de desenvolvimento do projeto (ARAÚJO, 2007, p. 166).

Kvan (1999) apud Araújo (2007, p. 166), observa que "o ateliê virtual de projeto deve expor os estudantes ao processo de projeto e não focar apenas nos resultados finais". A colaboração pode promover o intercâmbio entre os participantes, inclusive em produtos intermediários, e quebrar a abordagem individualista focada no produto, ainda existente nos ateliês de hoje. Araújo (2007, p.167) afirma que o "atelier virtual exige maior concentração, empenho, tempo e inclusive [...] desprendimento, para melhor compreender eventuais mensagens 'truncadas'”. Ou seja, ressalta-se o caráter de intercâmbio cultural dos ateliês virtuais. Não se trata de uma novidade advinda das tecnologias da informação e da comunicação, mas facilitadas por elas; "[...] ainda não são parte do cotidiano das escolas de arquitetura brasileiras", com poucos exemplos, como o Habitar a Cidade e o Taller Virtual de Las Americas.

[...] quanto maior o acesso às demais culturas, tanto de projeto, como regional, melhor será para a formação do arquiteto. Ao conhecer o "outro", e por ele se deixar conhecer, o aluno, professor ou arquiteto entende que suas dúvidas e incertezas são, na verdade, temores universais, mas que podem ser superadas com o auxílio do diálogo. (ARAÚJO, 2007, p. 167).

Maher e Simoff (2006) afirmam que o uso de ambientes para desenvolvimento de projetos colaborativos mediados por computador tem se difundido. Existem diferentes modos de viabilizar essa ideia. Os autores apresentam algumas alternativas: ambiente colaborativo como um estúdio de design (metáfora do lugar, com variações: o lugar é modelado no estúdio e o local é um modelo do objeto ou edifício que está sendo projetado).

É um contexto que exige um posicionamento claro e rápido, pois, de um lado, é forte a pressão do capital para a implantação do EaD ou mesmo difusão de tecnologias da informação para o ensino remoto, sem garantir a todos as devidas condições e sem uma suficiente avaliação do aprendizado de determinados recursos; de outro lado, as transformações sociais são amplas e não podem ser analisadas sem a presença das Tls. Ou seja, os recursos tecnológicos, que avançaram e estão cada vez mais intuitivos e acessíveis, também motivadas pela necessidade do isolamento social, avançam nas relações de trabalho, e nos seu modus operandi, numa velocidade não prevista.

\section{CONSIDERAÇÕES FINAIS}

O público da graduação é a Geração do Milênio (se não a Geração Z, dos nascidos entre os anos 2000 e 2010, que já chegaram ao mundo quando smartphones e internet já faziam parte do cotidiano global), que vive conectada, desenvolve multitarefas, e lida com a tecnologia com velocidade. Esses jovens precisam de reconhecimento, são imediatistas e em geral impacientes. Eles têm muitas características diferentes das nossas; e muitas vezes, temos dificuldade de entender. Fazem várias atividades ao mesmo tempo estudam enquanto nos ouvem. As suas condições de trabalho nem sempre são muito adequadas e não é surpresa saber que enquanto assistem aula, estão realizando alguma atividade doméstica ou junto com outras pessoas. Não é incomum que muitos apresentam resistência para ligar a câmera e/ou o áudio.

Com base em uma breve pesquisa, não parece haver muita inovação, do ponto de vista pedagógico, no ensino remoto de arquitetura nesses tempos de pandemia. Em geral, ocorreu uma adaptação do modo tradicional de ensino de projeto para o modo remoto (mediado por algumas tecnologias convencionais, não específicas de arquitetura). Trata-se de uma questão para pensarmos. Como corrigir problemas do atelier tradicional no contexto atual? Curiosamente, ensino remoto em outras áreas, como engenharia da computação, engenharia de software etc., tem experimentado práticas pertinentes, que podem inspirar o 
aperfeiçoamento daquilo que já é feito no ensino de projeto de AU de forma presencial, como a substituição das aulas expositivas convencionais por atividades programadas, desenvolvimento da colaboração nas atividades assíncronas, desenvolvimento da autonomia dos estudantes, ciclos de micro interações, exercícios contínuos, curadoria de informações, aprendizado a partir do erro.

Podemos elencar vários elementos que limitam ou favorecem as experiências de ensino remoto de projeto de AU. Sobre os elementos limitantes, destacam-se os desafios de: a) lidar com a ineficiência das ferramentas e da infraestrutura (o microfone não funciona, a energia cai, a internet falha, equipamentos impróprios, espaços de trabalho em casa inadequados etc.); b) dispensar muita energia para continuidade das aulas (no atual contexto, tem sido necessário um esforço enorme dos professores e dos estudantes); c) redobrar as atenções aos problemas particulares dos estudantes e dos colegas decorrentes da pandemia (questões de saúde, financeiros, etc.); d) flexibilizar (ou inclusive baixar) o grau de exigência das atividades realizadas; e) dedicar mais tempo para preparação das aulas e para avaliação de trabalhos; f) ausência da interação presencial entre os docentes e os estudantes, bem como entre os próprios estudantes (nos átrios, nas cantinas, e outros espaços de convívio).

Com respeito aos elementos favoráveis, podemos observar as possibilidades de: a) reconhecer as potencialidades e os limites da tecnologia; b) aprender novos recursos (apps, softwares, etc.); c) repensar estratégias metodológicas auxiliadas por Tls; d) experimentar novas possibilidades de explorar a autonomia dos estudantes; e) lidar com o alcance das ações em aula de projeto (presencial é para um grupo reduzido, no ambiente virtual ampliamos o público); f) compartilhar referências com mais facilidade; $g$ ) reaprender a gerir o tempo e filtrar informações; h) desenvolver nos discentes competências e habilidades importantes para atuação na sociedade (Espinal, 2018, elenca 5 áreas de atuação em tecnologia de arquitetura: Diretor de Tecnologia, Modeladores de Realidade Imersiva, Designers de Simulação Virtual, Designers de Interface Háptica, Cientistas / Analistas de dados); i) realizar atividades entre diferentes escolas do país e de outros países; j) desenvolver novas modos de desenvolvimento de processos colaborativos interculturais e inter áreas. Naturalmente, se tratam de realidades e possibilidades que resultam ou podem resultar de contextos muito distintos.

Com respeito aos recursos e às estratégias que podem ser adotados para tornar a experiência de ensino remoto mais adequada, observamos que, naturalmente, essas mudanças já demandam investimentos em espaços domésticos adequados para abrigar o home office nos espaços residenciais. Um cômodo específico para atividades de trabalho já parece necessário no atual contexto. Também, é importante destacar alguns itens de infraestrutura necessários para instituições, professores e estudantes: a) internet confiável (planos melhores); b) computadores com configurações adequadas; c) tela complementar; d) assistente para o professor (monitor). As estratégias devem ser pensadas, considerando 0 desenvolvimento de competências e habilidades importantes nestes tempos (multidomínios e multimeios, equilíbrio emocional, autonomia, capacidade para pesquisa e critério para filtrar informações), recursos disponíveis e valores importantes (que não devem se perder, como o exercício de vivenciar e perceber o espaço, bem como a interação interpessoal).

Podemos concluir que o nosso problema maior, mais do que as ferramentas tecnológicas (como dito, já presentes há bastante tempo) é: como conseguiremos garantir condições de trabalho dignas aos professores e uma boa qualidade de formação aos estudantes neste contexto? É preciso desenvolver muitas pesquisas para avaliação do aprendizado dos estudantes. Ao mesmo tempo que devemos resistir com ênfase e clareza ao modelo de educação como mercadoria em escala industrial; precisamos repensar o modo tradicional (artesanal) de realização do atelier. As tecnologias amplificam as nossas capacidades, não as substituem. Precisam ser aproveitadas de forma criteriosa e responsável. A parte de tudo isso, espera-se que essa pandemia, que tem revelado uma realidade social tão dura, com tantas desigualdades sociais, que precisam ser corrigidas, nos restaure a prática de termos mais atenção e solidariedade uns com os outros.

\section{REFERÊNCIAS}

WILDEROM, Mariana; ARANTES, Pedro Fiori. "Arquiteturas da distância: o que a pandemia pode revelar sobre o ensino de Arquitetura e Urbanismo". 02 Ago 2020. ArchDaily Brasil. Acessado 3 Out 2020. $<$ https://www.archdaily.com.br/br/944738/arquiteturas-da-distancia-o-que-a-pandemia-pode-revelar-sobre-o-ensino-dearquitetura-e-urbanismo > ISSN 0719-8906.

ARAÚJO, Tereza Cristina Malveira de. Projetos Colaborativos. Experiências Interculturais na Formação do Arquiteto. Rio de Janeiro: UFRJ/ FAU, 2007. 204f. Tese (doutorado) - Universidade Federal do Rio de Janeiro, Faculdade de Arquitetura e Urbanismo, Programa de Pós-graduação em Arquitetura, 2007. 
BRADY, Ross. "Seria o aprendizado online o futuro do ensino de arquitetura?" [Architecture Education is Unhealthy, Expensive, and Ineffective. Could Online Learning Change That?] 10 Mai 2020. ArchDaily Brasil. (Trad. Moreira Cavalcante, Lis) Acessado 3 Out 2020. <https://www.archdaily.com.br/br/884716/cursar-arquitetura-nao-e-saudavel-ecaro-e-ineficaz-a-aprendizagem-online-pode-mudar-isso> ISSN 0719-8906 ESPINAL, Hilda. Sobre futuras áreas de atuação (em tecnologia de arquitetura). Archdaily, 2018. Disponível em: <https://www.archdaily.com.br/br/886728/5carreiras-emergentes-em-tecnologia-de-arquitetura-para-prestar-atencao-a-partir-de2018?ad medium=widget\&ad name=recommendation $>$.

MAHER, Mary Lou; SIMOFF, Simeon. Variations on the Virtual Design Studio. Department of Architectural and Design Science. University of Sydney, NSW, 2006. AUSTRÁLIA.

PORTER, Luis; MIGLIOLI, Viviana. La enseñanza de la arquitectura hoy, las limitaciones del modelo de taller de proyecto y las alternativas posibles. Arquitextos, São Paulo, año 18, n. 210.04, Vitruvius, nov. 2017 <https://www.vitruvius.com.br/revistas/read/arquitextos/18.210/6794>.

RÊGO, Maria Carmem Freire Diógenes; GARCIA, Tânia Cristina Meira. Ensino remoto e educação a distância são a mesma coisa? Material didático disponibilizado em capacitação na UFRN, 2020.

\section{NOTAS}

1 O Ministério da Educação (MEC), que muitas vezes atua como um parceiro dessas instituições, editou portaria, ํo 2.117 , de 06 de dezembro de 2019, que permite a oferta de até $40 \%$ da carga horária de cursos superiores na modalidade presencial na modalidade $\mathrm{EaD}$, exceto Medicina. O texto revoga as normas vigentes na ocasião que admitiam até $20 \%$.

NOTA DO EDITOR $\left(^{*}\right)$ : O conteúdo do artigo e as imagens nele publicadas são de responsabilidade do(s) autor(es). 